\title{
Probing of congenital nasolacrimal duct obstruction with dacryoendoscope
}

\author{
This article was published in the following Dove Press journal: \\ Clinical Ophthalmology \\ 16 May 2014 \\ Number of times this article has been viewed
}

\section{Kumiko Kato \\ Koichi Matsunaga \\ Yuko Takashima \\ Mineo Kondo}

Department of Ophthalmology Mie University School of Medicine, Tsu, Japan
Correspondence: Kumiko Kato Department of Ophthalmology, Mie University School of Medicine, 2-174 Edobashi,Tsu-shi, Mie,

519-8507, Japan

Tel +81592315027

Fax +81592313036

Email k-kato@clin.medic.mie-u.ac.jp
Background: A congenital nasolacrimal duct obstruction (CNLDO) is a relatively common disease in infants. We evaluated the results of probing three patients with CNLDO, under direct view, with a dacryoendoscope.

Methods: Three cases of CNLDO were examined and treated by probing with a dacryoendoscope, under intravenous anesthesia. The diameter of the dacryoendoscope probe was $0.7 \mathrm{~mm}$, and we were able to observe the inner walls of the lacrimal duct and able to guide the probe through the duct.

Results: In all cases, the site of obstruction was detected, and the probe was used to remove the obstruction. At 2 weeks after the removal of the obstruction, there was no epiphora or mucopurulent discharge in any of the cases. No complications were detected intra- and postoperatively. Conclusion: Although only three cases were studied, we believe that probing with a dacryoendoscope is a safe and effective method of treating a CNLDO. More cases need to be studied.

Keywords: probing, epiphora, mucoprulent discharge

\section{Introduction}

A congenital nasolacrimal duct obstruction (CNLDO) is a relatively common ophthalmic problem of the newborn, with up to $70 \%$ having a membranous obstruction of the duct. ${ }^{1}$ However, only $20 \%$ of all neonates have symptoms of a CNLDO. ${ }^{2}$ The canalization of the nasolacrimal duct at the nasal end is not complete until birth, and CNLDO is caused by the presence of a membrane covering the opening of the lacrimal duct into the nasal canal. If the membranous obstruction persists, the parents may observe epiphora and discharge from the eye.

CNLDOs can resolve spontaneously without treatment, and most cases are resolved without treatment by the first birthday. ${ }^{2-6}$ Because the incidence of CNLDO is high and spontaneous resolution common, a CNLDO is generally regarded to be within the range of normal development. ${ }^{7}$ However, about $20 \%$ of newborn infants have epiphora and/or discharge from the eye.

Probing of the lacrimal duct has been advocated as a first-line management of a CNLDO in Japan because it can be performed under topical anesthesia without special equipment. However, probing of the lacrimal system is generally performed blindly, and the probe can penetrate the submucosal space or lacerate the canaliculi of the lacrimal duct. These complications may prevent a spontaneous canalization of the duct. $^{7}$ To overcome deficiency of blind probing, a dacryoendoscope was developed in Japan. ${ }^{8}$ The probing system is equipped with a fiber optic viewing system that allows the clinician to guide the probe through the lacrimal canaliculi. The diameter of the probe is $0.7 \mathrm{~mm}$, which is suitable for children. It is considered to be safe because it allows a view of the intralacrimal duct, which reduces the possibility of lacerations 
of the canaliculi. In addition, it can detect the site of the obstruction and treat CNLDO.

We report our findings in three cases of CNLDO treated by dacryoendoscopic canalicular probing, with successful outcome and no complications.

\section{Methods}

We studied the lacrimal systems of three children whose diagnosis of CNLDO was based on a history of epiphora, delay in lacrimal outflow using the fluorescein disappearance test (FDT), ${ }^{9}$ and the results of lacrimal duct irrigation. The initial examination included identifying the lacrimal puncta, searching for anomalies of the lids, and ruling out conjunctivitis, allergic inflammation, and craniofacial abnormalities. All children had digital massage over the lacrimal sac and received topical antibiotics as needed. The parents were also given instructions on lid hygiene.

The dacryoendoscope we used was the RUIDO FT-203F Fiberscope MD3 (FiberTech Co., Ltd., Tokyo, Japan), which features a probe with an outer diameter of $0.7 \mathrm{~mm}$, an angle of view of 60 degrees, 3,000 elements in the image, and an observation depth of $1 \mathrm{~mm}$ to $10 \mathrm{~mm}$. The endoscope consisted of a viewing lens, fiber optic cable, and a water channel with a polyimide resin coat. The images were displayed on a monitor.

Under intravenous anesthesia, the upper or lower lacrimal punctum was dilated, and the probe was inserted through the punctum into the canaliculus (Figure 1). Saline was injected through the water channel, which allowed a better view of the lumen. The occluded area was usually felt as an obstruction of the movement of the probe, and the obstruction was confirmed by the video images displayed on the monitor.

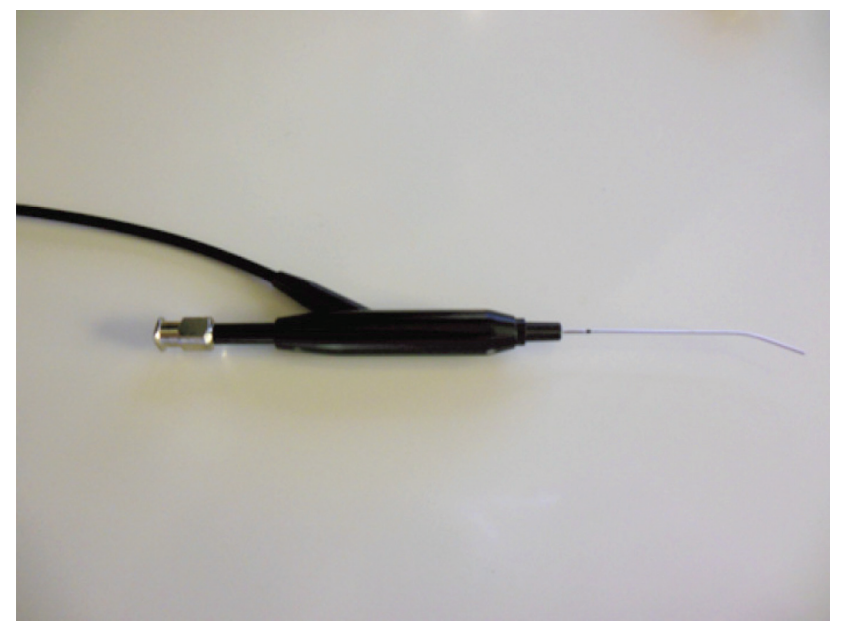

Figure I Photograph of the 23G RUIDO fiberscope (FiberTech Co., Ltd., Tokyo, Japan).
Then, the obstruction was opened by pressure by the tip of the probe. When the tip of the probe entered the nasal cavity, the mucous membrane of the nasal cavity could be observed.

The procedures used conformed to the tenets of the World Medical Association's Declaration of Helsinki. A written informed consent was obtained from the parents of each of the patients after they were provided with sufficient information on the procedures to be used.

\section{Case I}

An 8-month-old boy with bilateral epiphora and mucopurulent discharge since infancy was seen in consultation. There was no history of nasolacrimal duct probing, but both nasolacrimal ducts had been irrigated with saline when he was 2 months of age. Although the epiphora and mucopurulent discharge had decreased, epiphora and mucoprulent discharge soon recurred and FDT demonstrated a delayed clearance. The signs in the right eye decreased when the child was 12 months of age, but at 20 months, the left nasolacrimal duct remained occluded. After our general examination, we decided to probe the lacrimal ducts with a dacryoendoscope, and we found that there was no fibrosis in the lacrimal sac (Figure 2). An obstruction of the nasolacrimal duct was found and opened by pressure of the probe, and the nasal cavity could be seen through the dacryoendoscope.

Two weeks after the probing, there was no epiphora or mucopurulent discharge, and there was no recurrence after 6 months.

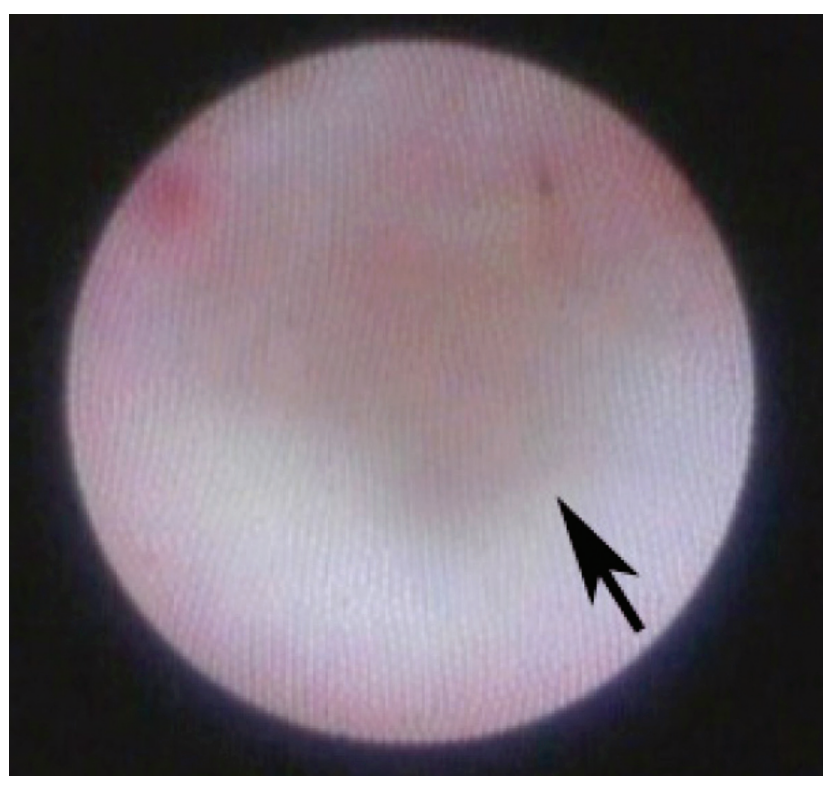

Figure 2 Dacryoendoscopic image of the lacrimal sac. The wall of the lacrimal sac is smooth with no fibrosis. There is a dimple (arrow) in the lacrimal sac. 


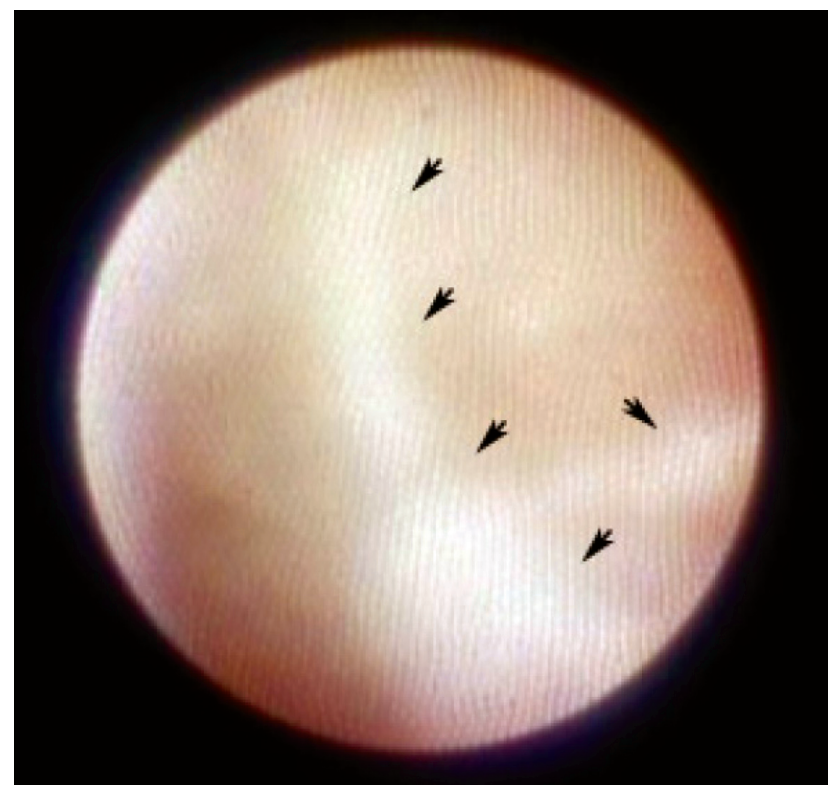

Figure 3 Dacryoendoscopic image showing fibrosis in the lacrimal sac (arrows). The lumen is to the left of the fibrosis.

\section{Case 2}

A 12-month-old girl with epiphora and mucopurulent discharge from the left eye since infancy was seen in consultation. She had a history of lacrimal duct probing. FDT of the left eye confirmed a delay of clearance. Because the left nasolacrimal duct remained blocked, when she was 18 months of age, the duct was probed with a dacryoendoscope. Fibrosis tissue was detected at the entrance into the lacrimal sac, but we were able to see a dimple at the bottom of the lacrimal sac (Figure 3). There was no sign of past probing, and the obstruction remained. As we guided the probe deeper, we felt an obstruction at the position of the dimple, and further pressure with the probe penetrated the obstruction. At this time, the nasal cavity could be seen through the dacryoendoscope.

Two weeks after the probing, there was no epiphora or mucopurulent discharge, and there was no recurrence after 6 months.

\section{Case 3}

A 9-month-old boy who had bilateral epiphora and mucopurulent discharge since infancy was seen in consultation. He had a history of probing of the nasolacrimal duct, but FDT showed delayed clearance in both eyes. When he was 16 months of age, the obstruction of the left nasolacrimal duct spontaneously cleared; however, the right nasolacrimal duct remained blocked. When he was 19 months of age, the duct was examined with a dacryoendoscope, and fibrotic tissue was seen in the lacrimal sac. An obstruction was seen at the bottom of lacrimal sac, and the obstruction was opened by pressure of the probe.

Two weeks after the probing, there was no epiphora or mucopurulent discharge, but after a few months, there was a recurrence of epiphora and mucopurulent discharge in the right eye.

\section{Discussion}

CNLDO has been treated by different methods, eg, digital massage, blind probing, irrigation, silicone intubation, and balloon dilation of the nasolacrimal duct. ${ }^{10}$ Among these, probing of the duct has been mainly used, when digital massage fails. Recently, a large-scale prospective study reported that the probability of successful results of probing for CNLDO was 78\%. ${ }^{11} \mathrm{~A}$ spontaneous resolution of CNLDO occurred in over $80 \%$ of infants, which continued through the first year of life. ${ }^{2-7}$ The incidence of spontaneous resolution has been found to be $80 \%-90 \%$ at 3 months of age, $68 \%-75 \%$ at 6 months, and $36 \%-57 \%$ at 9 months of age. ${ }^{3,4,6}$ Based on these findings, probing before 12 months of age should be withheld if there are no symptoms of dacrocystitis and severe blepharitis. There have been reports that prolonged inflammation will promote fibrosis at the obstructed site, ${ }^{12,13}$ but recent evidence does not support this. ${ }^{14}$ Furthermore, CNLDO is not always accompanied by inflammation, and late probing does not always result in fibrosis of the obstructed site.

In Japan, probing has been performed in the clinic because it is easy to perform under topical anesthesia, without special equipment. ${ }^{3}$ However, it can sometimes cause complications, including laceration of the canaliculus and perforation, of the lacrimal duct or sac, by the probe. Unsuccessful initial probing can result in cicatricial strictures, fibrosis, and a false passage, all of which can lead to fibrosis. The fibrosis will then reduce the success of future surgeries and reduce the incidence of spontaneous resolution. ${ }^{7}$ Lyon et al reported that iatrogenic canalicular obstructions can develop in $44 \%$ of the cases undergoing probing. ${ }^{15}$ Also, the cure rate of repeated probing is greatly decreased, ${ }^{16-18}$ and serial probings should be avoided. To prevent iatrogenic obstructions, a wait-and-see policy, combined with conservative therapy and treatments such as single probing, silicone tube intubation, and balloon catheter dilation are preferable.

The dacryoendoscope we used was released in Japan in 2002. Since then, adult patients and neonates with CNLDO with nasolacrimal duct obstruction (NLDO) have been probed with direct observation of the obstructed duct to avoid false passage. Institutions treating NLDO in adults can 
perform dacryoendoscopic probing for CNLDO with only the $0.7 \mathrm{~mm}$ probe. The images obtained from the $0.7 \mathrm{~mm}$ probe are made up of 3,000 pixels, which is lower than for typical endoscopes, eg, gastroscopes and nasal endoscopes. But blind probing of the lacrimal system requires considerable skill and experience, and dacryoendoscopy enabled us to observe the lacrimal duct directly. Dacryoendoscopy is probably even safe for the ophthalmologist who performs only an occasional probing.

In conclusion, we performed dacryoendoscopic canalicular probing in three cases of CNLDO. Two of the cases had a history of probing, and we were able to observe fibrosis in the lacrimal duct by dacryoendoscopy. On the other hand, there was no fibrosis in the case without a history of probing. These observations support earlier reports that probing can cause iatrogenic nasolacrimal duct fibrosis, which can worsen the obstruction. ${ }^{7,15}$ Our findings show that dacryoendoscopic canalicular probing may be the safe treatment for CNLDO.

\section{Disclosure}

The authors report no conflicts of interest in this work.

\section{References}

1. Cassady JV. Developmental anatomy of nasolacrimal duct. AMA Arch Ophthalmol. 1952;47(2):141-158.

2. MacEwen CJ, Young JD. Epiphora during the first year of life. Eye (Lond). 1991;5(Pt 5):596-600.

3. Kakizaki H, Takahashi Y, Kinoshita S, Shiraki K, Iwaki M. The rate of symptomatic improvement of congenital nasolacrimal duct obstruction in Japanese infants treated with conservative management during the 1st year of age. Clin Ophthalmol. 2008;2(2):291-294.

4. Petersen RA, Robb RM. The natural course of congenital obstruction of nasolacrimal duct. J Pediatr Ophthalmol Strabismus. 1978;15(4): $246-250$.
5. Nelson LB, Calhoun JH, Menduke H. Medical management of congenital nasolacrimal duct obstruction. Ophthalmology. 1985;92(9): 1187-1190.

6. Paul TO. Medical management of congenital nasolacrimal duct obstruction. J Pediatr Ophthalmol Strabismus. 1985;22(2):68-70.

7. Young JD, MacEwen CJ. Managing congenital lacrimal obstruction in general practice. BMJ. 1997;315(7103):293-296.

8. Sasaki T, Nagata Y, Sugiyama K. Nasolacrimal duct obstruction classified by dacryoendoscopy and treated with inferior meatal dacryorhinostomy. Part I: Positional diagnosis of primary nasolacrimal duct obstruction with dacryoendoscope. Am J Ophthalmol. 2005;140(6): 1065-1069.

9. MacEwen CJ, Young JD. The fluorescein disappearance test (FDT): an evaluation of its use in infants. J Pediatr Ophthalmol Strabismus. 1991;28(6):302-305.

10. Takahashi Y, Kakizaki H, Chan WO, Selva D. Management of congenital nasolacrimal duct obstruction. Acta Ophthalmol. 2010; 88(5):506-513.

11. Pediatrics Eye Disease Investigator Group; Repka MX, Chandler DL, Beck RW, et al. Primary treatment of nasolacrimal duct obstruction with probing in children younger than 4 years old. Ophthalmology. 2008; 115(3):577-584.

12. Broggi RJ. The treatment of congenital dacryostenosis. AMA Arch Ophthalmol. 1959;61(1):30-36.

13. Ffooks OO. Dacryocystitis in infancy. Br J Ophthalmol. 1962;46(7): 422-434.

14. MacEwen CJ, Phillips MG, Young JD. Value of bacterial culturing in the course of congenital nasolacrimal duct (NLD) obstruction. J Pediatr Ophthalmol Strabismus. 1994;31(4):246-250.

15. Lyon DB, Dortzbach RK, Lemke BN, Gonnering RS. Canalicular stenosis following probing for congenital nasolacrimal duct obstruction. Ophthalmic Surg. 1991;22(4):228-232.

16. Pollard ZF. Tear duct obstruction in children. Clin Pediatr (Phila). 1979; 18(8):487-490.

17. Katowitz JA, Welsh MG. Timing of initial probing and irrigation in congenital nasolacrimal duct obstruction. Ophthalmology. 1987; 94(6):698-705.

18. Honavar SG, Prakash VE, Rao GN. Outcome of probing for congenital nasolacrimal duct obstruction in older children. Am J Ophthalmol. 2000;130(1):42-48.
Clinical Ophthalmology

\section{Publish your work in this journal}

Clinical Ophthalmology is an international, peer-reviewed journal covering all subspecialties within ophthalmology. Key topics include: Optometry; Visual science; Pharmacology and drug therapy in eye diseases; Basic Sciences; Primary and Secondary eye care; Patient Safety and Quality of Care Improvements. This journal is indexed on Submit your manuscript here: http://www.dovepress.com/clinical-ophthalmology-journal

\section{Dovepress}

PubMed Central and CAS, and is the official journal of The Society of Clinical Ophthalmology (SCO). The manuscript management system is completely online and includes a very quick and fair peer-review system, which is all easy to use. Visit http://www.dovepress.com/ testimonials.php to read real quotes from published authors. 